\title{
The Change in Productivity of Chinese State Enterprises, 1983-1987
}

\author{
ROGER H. GORDON \\ Department of Economics, University of Michigan, Ann Arbor, MI 48109, Roger.Gordon@umich.edu \\ WEI LI \\ Fuqua School of Business, Duke University,Box 90120,Durham, NC 27708-0120, WL4@mail.duke.edu
}

\begin{abstract}
This study estimates the change in productivity of Chinese state enterprises during 1983-1987 using a panel data set of 403 firms. A new approach to productivity measurement is ased. Under this approach, the production functions can differ arbitrarily across firms, important given the heterogeneity of the sample. The resulting coefficients estimate the marginal products of each factor as well as overall productivity growth. The results suggest Chinese productivity increased by $4.6 \%$ per year, with about half of this growth due to the rapidly improving education of the labor force.
\end{abstract}

Keywords. Productivity, Chinese enterprise reforms

\section{Introduction}

Between 1983 and 1987, the People's Republic of China changed the administration of state-owned enterprises in a variety of ways in an attempt to increase their efficiency. During 1983 and 1984, an explicit tax system was introduced, affecting most state-owned enterprises. While marginal tax rates were very high, given the combined effects of the income tax, the adjustment tax, and the return of depreciation allowances to the government, firms were still able to retain more of their profits than had been the case in the past, increasing their incentive to be efficient. While the government specified what fraction of after-tax profits should be used for new investment $v s$. worker bonuses and benefits, firms were still given much more discretion over their internal operations than they had in earlier years, allowing them to respond to these new incentives. By 1987, many firms signed contracts with the government specifying minimum tax payments and sometimes minimum investment rates. Detailed provisions in the contracts varied by firm. Under these contracts, marginal tax rates were often very low. During this period, there was a further relaxation of direct government controls over state-enterprise decision-making. The intent was to imitate the design of the responsibility system in agriculture that had been such a success. ${ }^{1}$ In addition to these broad changes in policy, a number of experimental policies were instituted on a smaller scale.

The basic objective of these policy changes was to raise the efficiency of state-owned enterprises. Different stages of the reforms aimed at different aspects of efficiency. First, allowing firms to retain a larger fraction of profits, and linking the pay of workers more closely to profits, should have increased work effort and reduced stockpiles of inputs. As a result, it was hoped that each firm would produce more, for any given allocation of inputs. 
Second, forcing firms to sell directly to customers, and eliminating the right to sell unwanted goods to a government procurement agency, gave firms the incentive to change their product mix. Third, the allocation rules for factors changed substantially. Under the profit retention rules, firms had to allocate some fraction of profits to new investment, implying more investment by the more profitable firms. ${ }^{2}$ Bank loans replaced government grants as the main alternative source of finance, presumably leading to more attention to the firm's ability to repay any loan. These new allocation rules could well have changed the efficiency with which factors were allocated across firms, shifting inputs from firms where the value of their marginal product was low to firms where the value of their marginal product was high. There were no explicit labor, capital, or land markets in China during this period, however, restricting firms' ability to improve efficiency in this sense.

The objective of this paper is to make use of survey data on 403 state-owned enterprises, to measure the changes in the productivity of these firms between 1983 and 1987, to assess the effectiveness of these reforms. In the process, we also estimate the value of the marginal products of each factor, and the degree to which they vary across firms. This allows us to measure the degree to which productivity growth during the period arose from a reallocation of factors toward more productive firms, as well as from each firm becoming more productive.

The survey used was designed by members of the Institute of Economics in the Chinese Academy of Social Sciences, in collaboration with American and European economists. The 403 firms included in the survey were located in many different regions of China, and include firms in many different industries and of many different sizes. The State Statistical Bureau administered the survey during September 1988. The data are roughly comparable in scope to the Compustat data, though covering six years (1980 plus 1983-1987) rather than twenty years. In addition, there is a supplementary data set describing the links between each firm and the government. ${ }^{3}$

Existing techniques for estimating productivity growth and marginal products of factors proved to be inappropriate in this context. In particular, the sample included firms in thirty different two-digit industries, so that we could not plausibly assume a common parametric production, profit, or cost function for these firms. Given the limited nature of the economic reforms, we could not even assume that these firms act to maximize profits or minimize costs. We therefore developed a new approach to estimate productivity growth, in which the observed changes in outputs are compared with those for inputs during the sample period. Productivity growth is measured by the degree to which output growth is larger than can be explained by input growth.

In Section 1, we describe the theoretical approach used to assess the degree to which the productivity of state-owned enterprises has changed under the reforms, and where and when these improvements have been largest. In Section 2, we discuss how the survey data were used to estimate the desired expressions measuring productivity change, while the resulting estimates are reported and described in Section 3. The final section provides a brief summary of our main results.

\section{Theoretical Approach to Estimating Productivity Change}

In any given year, the real output of a firm depends on the quantities of the various inputs it has available in production, and on the regulatory structure and incentives that it faces. If 
we assume that changes in the regulatory structure and incentives affect output in a Harrod neutral fashion, then the real output, $Q_{e s}$, of enterprise $e$ in year $s$ measured in the prices of some base year $t$ can be written as

$$
Q_{e s}=F^{e}\left(K_{e 1 s}, \ldots, K_{e N s}\right) G^{e}\left(X_{e 1 s}, \ldots, X_{e M s}\right) \text {, }
$$

where $K_{\text {eis }}$ measures the real amount of the $i$ th input available to the firm in year $s$, while $X_{e j s}$ measures the $j$ th characteristic of the regulatory environment affecting the firm in year $s$.

The traditional approach used to estimate productivity change is to estimate equation (1) directly, assuming some parametric form for the function $F$, common for all firms, along with some parametric specification for the function $G .{ }^{4}$ In many cases, authors simply assume that the function $F$ is Cobb-Douglas, and that the function $G$ captures exponential growth. But this assumption of a common production function is hardly plausible given that our sample includes such a diverse set of firms. Imposing this assumption when inappropriate would lead to a variety of mistaken inferences. For example, if firms have a common technology then efficiency requires equal factor proportions for all firms. As a result, this assumption implies that any variation in factor proportions within the sample results from a misallocation of factors. While factor proportions certainly vary among the firms within our sample, it seems inappropriate to impose this inference on the results. In addition, under this assumption firms with extreme factor proportions would be forecast to be less profitable everything else equal, given that they have not minimized costs at the market prices for the factors. If these firms with extreme factor proportions do not in fact have sufficiently lower profits, then under the assumption of a common technology we would infer that they are more efficient. Again, it seems inappropriate to impose such a conclusion a priori.

Recent advances in methodology in productivity research, in particular, the stochastic frontier production approach [Schmidt and Lovell (1979), Forsund et al. (1980), Bauer (1990) and many others] and the distance function approach [Fare et al. (1992)], also require production technology to be identical up to one or two intercept terms across firms. Therefore, they also are not applicable to such a diverse sample of firms. There are also strands of literature that measure improvement in productivity and allocative efficiency by estimating a frontier profit function [Lovell and Sickles (1983), Sickles et al. (1986)] or a frontier cost function [Atkinson and Halverson (1984), Kumbhakar (1993) and Atkinson and Cornwell (1994)]. But it would be presumptuous to assume a priori that Chinese firms in this period act to maximize profits or minimize costs-in fact most inputs in China were allocated by higher authorities rather than chosen by firms. In any case, given the lack of labor or capital markets, there were no market-clearing prices for these factors, prices which are needed in the estimation of profit or cost functions.

In order to allow the shape of production functions to differ arbitrarily across firms, we make no attempt to compare the level of productivity of different firms in this study. Instead, we focus on changes in productivity over time within each firm by comparing changes in a firm's output over time with changes in its inputs. To the extent to which output growth is larger than can be explained by input growth, we infer that productivity has increased. ${ }^{5}$ In the process, we can estimate the pattern of variation of the marginal product 
of each factor across firms. If a factor is indeed allocated efficiently across firms, then its marginal products will be the same in all firms regardless of differences in the underlying technology across firms. Within the model, deviations from efficient factor allocations are allowed to occur in response to both observable and unobservable factors.

In particular, we take an exact finite difference of (1) between year $t$ and year $s$, making the change in the real value of output of enterprise $e$ between year $s$ and year $t$ a linear function of the changes in each of the $K_{e i s}$ and $X_{e j s}$. Doing so, we find that

$$
\Delta_{t s} Q_{e}=G^{e t} \sum_{i} \bar{F}_{i}^{e} \Delta_{t s} K_{e i}+F^{e s} \sum_{j} \bar{G}_{j}^{e} \Delta_{t s} X_{e j}
$$

where $\Delta_{t s} Y_{i}=Y_{i t}-Y_{i s}$ for any variable $Y_{i}, G^{e t}=G^{e}\left(X_{e l t}, \ldots, X_{e N t}\right)$,

$$
G^{e t} \bar{F}_{i}^{e}=G^{e t} \frac{F^{e}\left(K_{e 1 s}, \ldots, K_{e i t}, \ldots, K_{e N s}\right)-F^{e}\left(K_{e 1 s}, \ldots, K_{e i s}, \ldots, K_{e N s}\right)}{\Delta_{t s} K_{e i}}
$$

is a first-order approximation to the marginal productivity of factor $i$ in year $t, F^{e s}=$ $F^{e}\left(X_{e 1 s}, \ldots, X_{e N s}\right)$, and

$$
F^{e s} \bar{G}_{j}^{e}=F^{e s} \frac{G^{e}\left(X_{e 1 s}, \ldots, X_{e j t}, \ldots, X_{e M s}\right)-G^{e}\left(X_{e 1 s}, \ldots, X_{e j s}, \ldots, X_{e M s}\right)}{\Delta_{t s} X_{e j}}
$$

is a first-order approximation to the marginal response of real output to the change in policy $j$ in year $t$.

If each input $i$ had been allocated efficiently in year $t$, then the value of its marginal product would be equated across uses, implying that $G^{e t} \bar{F}_{i}^{e}=r_{i}$, for some implicit factor price $r_{i}$. In general, however, the value of the marginal product of factors could differ across firms. In the estimation, we will attempt to capture both systematic and nonsystematic variation across firms in these marginal products. In particular, we let

$$
G^{e t} \bar{F}_{i}^{e}=w_{i}+\sum_{k} Z_{k i}^{e} \rho_{k i}+\eta_{e i}
$$

where $Z_{k i}^{e}$ describes the $k$ th dimension along which the marginal product of the $i$ th factor may differ across firms, and where by construction $\eta_{e i}$ is uncorrelated with these $Z_{k i}^{e}$. Systematic variation in marginal products, for example, could arise due to heterogeneity in a factor, e.g., the marginal product of a worker varies depending on the education of the worker. If factors were allocated efficiently, the marginal product of a homogeneous factor should not differ systematically across firms, and the variance of $\eta_{e i}$ should be zero.

We can also use this approach to test whether factors were reallocated systematically between year $s$ and year $t$ toward firms where their marginal products were higher. To test whether firms receiving relatively larger factor allocations had higher marginal products for these factors, we simply set $Z_{1 i}^{e}=\left(\Delta_{t s} K_{e i} / Q_{e s}\right)$. If its coefficient, $\rho_{1 i}$, is greater than zero, then the reallocation of this factor between year $s$ and year $t$ raised efficiency. 
In order to end up with a specification capable of being estimated using the available data, we assume that each regulatory change leads to the same percent change in output in all affected firms, implying that $\vec{G}_{j}^{e} / G^{e s}$ does not vary with $e$. Denote this common value by $\beta_{j}$. In addition, in order to compensate for presumed heteroskedasticity, we divide equation (2) through by real output in year $s$ to get

$$
\frac{\Delta_{t s} Q_{e}}{Q_{e s}}=G^{e t} \sum_{i} \bar{F}_{i}^{e}\left(\frac{\Delta_{t s} K_{e i}}{Q_{e s}}\right)+\sum_{j}\left(\frac{\bar{G}_{j}^{e}}{G^{e s}}\right) \Delta_{t s} X_{e i}
$$

Finally, denote the combined effects of regulatory changes and changes in factor inputs not included explicitly in the final specification by $\nu_{e}$. Given these assumptions, equations (2a) and (3) together imply that

$$
\frac{\Delta_{t s} Q_{e}}{Q_{e s}}=\sum_{i}\left[w_{i}\left(\frac{\Delta_{t s} K_{e i}}{Q_{e s}}\right)+\sum_{k i} \rho_{k i} Z_{k i}^{e}\left[\frac{\Delta_{t s} K_{e i}}{Q_{e s}}\right]\right]+\sum_{j} \beta_{j} \Delta_{t s} X_{e j}+\epsilon_{e},
$$

where

$$
\epsilon_{e}=\sum_{i} \eta_{e i}\left(\frac{\Delta_{t s} K_{e i}}{Q_{e s}}\right)+\nu_{e}
$$

We estimate equation (4) using ordinary least squares, and use the White (1980) procedure to construct heteroskedastic consistent estimates of the standard errors of the coefficients.

Ordinary least squares estimation of equation (4) yields unbiased coefficient estimates if and only if $\epsilon_{e}$ is uncorrelated with any of the variables on the right-hand side of the equation. A variety of correlations are in principle possible. For example, the firms that are deregulated more quickly are not chosen randomly. Similarly, even though factors are allocated primarily by higher authorities, the resulting allocations may still depend on the observed performance of the firm. In each case, the government would most likely base these decisions on the level of accounting profits of the firm in previous years. The residual in equation (4), in contrast, measures unobserved effects causing changes in economic profits, where economic profits are measured based on implicit market prices rather than accounting prices for factors. There is no reason to expect much correlation between the level of past profits and the change in profits during the sample period. Also the substantial differences between accounting and economic profits would greatly attenuate any relationship. As a result, we expect that any biases in our estimates are minor. But in interpreting the coefficients the possibility of such biases must be recognized?

Coefficient estimates from equation (4) do not immediately give us a measure of productivity growth between year $s$ and year $t$, however. Overall productivity growth depends not only on the pattern of the regulatory changes, $\Delta_{t s} X_{e j}$, but also on the productivity of new vs. existing factor allocations. To provide a convenient summary measure of the size of overall productivity change, we therefore report the change in total factor productivity by industry, and for the aggregate sample. 
Following Kendrick (1973), aggregate total factor productivity in year $s$, denoted by $\Pi_{s}$, equals

$$
\Pi_{s}=\frac{\Sigma_{e} Q_{e s}}{\Sigma_{i} r_{i} K_{i s}},
$$

where real output, $Q_{e s}$ is measured in the prices of some base year $t$, where $K_{i s}=\Sigma_{e} K_{e i s}$, and where $r_{i}$ measures the value of the marginal product of factor $i$ in year $t$. An analogous productivity measure, $\Pi_{n s}$, can be defined for each industry $n$ in a given year, where

$$
\Pi_{n s}=\frac{\Sigma_{e \in n} Q_{e s}}{\Sigma_{i, e \in n} r_{i} K_{e i s}} .
$$

Given the presumed inefficiencies in the allocation of factors, there is a question about the appropriate definition of the $r_{i}$ 's. We chose to measure each of the $r_{i}$ by the average marginal product of new factor allocations between year $s$ and year $t$, as calculated using the estimates generated by equation (4). This implies that

$$
r_{i}=\hat{w}_{i}+\frac{\left(\Sigma_{e k} \hat{\rho}_{k i} Z_{k i}^{e} \Delta_{t s} K_{e i}\right)}{\Delta_{t s} K_{i}}
$$

The aggregate productivity change between years $s$ and $t$ is measured by $\Pi_{t}-\Pi_{s}$. It is straightforward to show that this expression equals

$$
\Pi_{t}-\Pi_{s}=\left[\frac{\Sigma_{e} \Delta_{t s} Q_{e}}{\Sigma_{e} Q_{e s}}-\sum_{i}\left[\frac{\Delta_{t s} K_{i}}{K_{i s}}\right]\left[\frac{r_{i} K_{i s}}{\Sigma_{f} r_{f} K_{f s}}\right]\right]\left[\frac{\Sigma_{e} Q_{e s}}{\Sigma_{i} r_{i} K_{i t}}\right] .
$$

The term in brackets is simply the difference between the percent increase in the value of output and a weighted average of the percent increases in each of the inputs, weighted by their relative costs, with the weights summing to one. If the rate of increase in output exceeds that for inputs, then productivity has increased.

Aggregate productivity change can also be expressed as

$$
\Pi_{t}-\Pi_{s}=\left(\sum_{e} \Delta_{t s} Q_{e}-\Pi_{s} \sum_{i} r_{i} \Delta_{t s} K_{i}\right) / \sum_{i} r_{i} K_{i t} .
$$

If $\Pi_{s}$ equals one, then the numerator in this expression equals the change in the profits generated by that enterprise between years $s$ and $t$, measured using the appropriate values and costs. When $\Pi_{s}>1,8$ then the value of output must increase proportionately more than the cost of inputs just to retain the initial level of productivity in the economy, and conversely.

\section{Empirical Implementation}

In order to estimate the coefficients in equation (4) or calculate any of the productivity measures, we need to construct values for each of the variables using the available data. 
Table 1. Percent inflation rates by year.

\begin{tabular}{lcccc}
\hline & \multicolumn{4}{c}{ Year } \\
\cline { 2 - 5 } Percent Change In & $1983-1984$ & $1984-1985$ & $1985-1986$ & $1986-1987$ \\
\hline Output Price & 1.64 & 3.97 & 4.68 & 3.80 \\
Capital Price & 12.69 & 15.02 & 7.38 & 15.21 \\
Equipment Price & 15.77 & 18.34 & 4.29 & 24.78 \\
Structure Price & 9.89 & 11.60 & 10.39 & 6.60 \\
Materials Price & 4.25 & 7.33 & 7.75 & 6.68 \\
Retail Price $^{\mathrm{a}}$ & 2.8 & 8.8 & 6.0 & 7.3 \\
\hline
\end{tabular}

${ }^{a}$ The retail price inflation rate comes from State Statistical Bureau (1989), p. 24.

In particular, we need values for real outputs, $Q_{e s}$, and real inputs, $K_{i s}$. We consider three inputs: labor, capital, and materials/fuel/power. Finally, we discuss summary measures of the economic reform policies that may have affected productivity. Each variable is discussed in turn.

\subsection{Real Output, $Q_{e s}$}

We need values for real output for each firm in each year, measured in the prices prevailing in some base year $t$. We use the last year of the survey as the base year, on the assumption that these relative prices are closer to relative market prices than are the prices in earlier years.9 In order to capture the effects of price changes during the sample period, we construct a separate measure of the inflation rate in output prices for each firm in each year, denoted by $\pi_{e s}$, then use these inflation estimates to convert nominal output in earlier years to nominal output in 1987 prices. Using a separate inflation correction for each firm is important, given the variation across firms as well as over time in the fraction of trade taking place at official vs. market prices.

Estimates of the inflation rate faced by each firm are constructed from responses to a question each year in which the firm was asked the effect of output price changes during the previous year on that year's sales revenue. The response should equal $\left[\left(p_{e s}-p_{e, s-1}\right)\right.$ / $\left.p_{e s}\right] S_{e s}$, where $S_{e s}$ denotes the firm's nominal output in year $s$. Dividing the response by $S_{e s}$ gives $\alpha_{e s} \equiv\left(p_{e s}-p_{e, s-1}\right) / p_{e s}$. It is easily shown that the inflation rate $\pi_{e s}$, defined to equal $\left(p_{e s}-p_{e, s-1}\right) / p_{e, s-1}$, can be estimated by $\alpha_{e s} /\left(1-\alpha_{e s}\right)$.

We used this procedure to calculate a separate inflation correction for each firm in each year, as long as the firm reported the needed data. ${ }^{10}$ If not, $\pi_{e s}$ was set equal to the weighted average value of the $\pi_{e s}$ in that year for firms with adequate data, weighting by sales revenue.

In Table 1, we report the weighted average inflation rates in each year. Here, we find that the measured inflation rate in ex-factory prices is much smaller than the inflation rate in retail prices, which was $6.2 \%$ per year on average between 1983-1987. This probably arises in part due to the tighter controls on the prices of industrial outputs, and in part due to firms choosing to sell at official prices, in order to avoid tax payments on any supplementary payments received in kind. 
In Table 2, we report the overall inflation between 1983 and 1987 by industry in column 1. The highest inflation rate is in building materials, which should not be surprising given the substantial building boom during the period, as well as the tightening of building standards that were gradually adopted in response to the Tangshan earthquake.

In selecting data for nominal output, we chose to use data on nominal sales rather than nominal production. ${ }^{11}$ By doing so, we assign a value to output only if a customer can be found so that the output does produce social value, and do not include output simply added to stockpiles. If and when the stockpiled output is sold, then it would be included in measured output. One problem with this approach is that output sold to government procurement agencies, and then stockpiled, is included in measured output, whereas if the firm stockpiles the output it would not be included. Since sales to government procurement agencies were more important at the beginning of the sample period, this will bias downwards our measure of output growth for firms producing some unwanted goods.

We report the aggregate annual percent growth in real output in Table 3 , and the overall percent growth between 1983 and 1987 by industry in Table 4, using the above definition of real output. Table 3 shows a steady growth in real output, reaching a double digit growth

Table 2. Annual percent inflation rates between $1983-1987$ by industry.

\begin{tabular}{lcc}
\hline \multicolumn{1}{c}{ Industry } & Output Price & Materials Price \\
\hline Mining & 4.53 & 2.92 \\
Utility & 2.76 & 10.94 \\
Food and Fodder & 3.19 & 1.90 \\
Beverage and Tobacco & 1.66 & 10.39 \\
Textile & 2.67 & 3.56 \\
Other Light & 5.86 & 10.11 \\
Chemical & 4.27 & 8.07 \\
Building Materials & 9.60 & 14.10 \\
Metallurgy & 2.87 & 8.44 \\
Machinery & 3.69 & 6.70 \\
Electric Equipment & 1.94 & 4.84 \\
Sample Average & & 7.37 \\
\hline
\end{tabular}

Table 3. Percent growth rates by year.

\begin{tabular}{lccrr}
\hline \multicolumn{1}{c}{ Growth Of } & \multicolumn{4}{c}{ Year } \\
\cline { 2 - 5 } & $1983-1984$ & $1984-1985$ & $1985-1986$ & $1986-1987$ \\
\hline Real Output & 5.71 & 7.42 & 11.72 & 10.07 \\
Real Capital & 7.53 & 9.12 & 13.58 & 23.50 \\
Real Materials & -0.15 & 7.53 & 12.66 & -2.32 \\
Labor & 4.83 & $-.71^{\mathrm{a}}$ & 1.47 & 2.01 \\
With College or Post-College Ed. & 7.95 & $10.57^{\mathrm{a}}$ & 8.60 & 12.61 \\
With Senior Secondary Ed. & 7.17 & $6.30^{\mathrm{a}}$ & 6.49 & 6.44 \\
With Junior Secondary Ed. or Less & .80 & $.44^{\mathrm{a}}$ & -.60 & -.96 \\
\hline
\end{tabular}

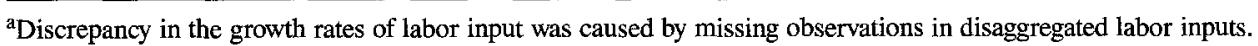


Table 4. Annual percent growth between $1983-1987$ by industry.

\begin{tabular}{lrrrr}
\hline \multicolumn{1}{c}{ Industry } & Output & Labor & Capital & Materials \\
\hline Mining & 4.75 & 3.32 & 8.60 & 3.96 \\
Utility & 1.32 & 2.17 & 4.53 & 2.94 \\
Food and Fodder & -.73 & 1.16 & 11.97 & 1.30 \\
Beverage and Tobacco & 12.47 & 4.62 & 21.36 & 9.96 \\
Textile & 5.99 & 1.92 & 11.87 & 3.33 \\
Other Light & 5.12 & .25 & 14.98 & 1.52 \\
Chemical & 5.10 & 4.15 & 11.18 & 3.82 \\
Building Materials & 3.71 & 1.44 & 7.79 & -2.30 \\
Metallurgy & 9.87 & .99 & 13.23 & .86 \\
Machinery & 11.00 & 1.45 & 8.48 & 9.05 \\
Electric Equipment & 18.59 & 2.65 & 11.27 & 19.76 \\
Sample Average & & & & 4.27 \\
\hline
\end{tabular}

rate during the last two years of our sample period. Output growth rates differed dramatically by industry, however, with real sales of the electronics industry virtually doubling between 1983 and 1987, and sales of food and fodder declining slightly in real terms.

\subsection{Labor Input, $K_{e l s}$}

We measure the labor input for a firm in year $s$ simply by the average number of workers at the firm over the course of the year, as reported in the survey. We did not make use of data on time loss due to work stoppages (due, for example, to shortages of raw materials), on the grounds that the opportunity cost of labor is measured by the potential work hours, not the actual work hours. Our procedure therefore captures efficiency gains arising from decreased stoppages. Table 3 reports the annual percent growth in the aggregate number of workers, while Table 4 reports the annual percent growth by industry in the number of workers between 1983 and 1987. Except during 1983-1984, the aggregate labor supply has been virtually constant in these firms. Even at the industry level, only in the utilities industry and the food and fodder industry was the growth rate in labor supply greater than the growth rate in output. Relative to other industries, the greatest growth in labor supply was in chemicals and in the beverage and tobacco industry.

To test for possible heterogeneity of labor, we allow the marginal product of labor to differ by level of education. In particular, we consider three different levels of education ( 8 years or less, 9 to 12 years, and more than 12 years). The percent growth rates of each of these categories of workers is listed by year in Table 3. As seen in the table, the quality of the labor force increased quickly during the period: the number of workers with some college education increased by $46 \%$ between 1983 and 1987, while the number with at most 8 years of education declined slightly. ${ }^{12}$

\subsection{Material, Fuel, and Power Inputs, $K_{e 2 s}$}

Real material inputs in each year are calculated based on the same approach used to calculate real output. In particular, the survey reports in each year the change in material, fuel, and 
power expenses from the previous year due to price changes. These figures are used as above to construct an inflation rate for materials for each firm..$^{13}$

Table 1 reports the weighted average inflation rate for materials in each year, while Table 2 reports the overall inflation between 1983 and 1987, by industry. In aggregate, the price of materials went up at almost twice the rate of output prices. The building-materials industry faced the greatest increases in prices for its material inputs, consistent with their having the greatest increase in output prices. The utilities industry had the second largest increase in material input prices, however, even though their output prices changed by less than the average for the sample as a whole.

It is interesting to compare the growth rate in the price of materials with the growth rate of the output prices in those industries that produce material inputs. For example, while the prices of material/fuel/power inputs went up by $33 \%$ during the period, the output prices from the chemicals, electronic, metallurgy, mining, and utilities industries, all of which in part produce material inputs for other industries, each went up by at most $19 \%$. How can the prices paid by firms for inputs they buy increase more quickly than the prices received by firms for inputs they sell? One explanation for this discrepancy, suggested to us in interviews with firm managers, is that firms selling materials may sometimes report only the cash component of the sale, while firms buying the materials report the total cost. ${ }^{14}$ The gap between the cash cost and the total cost of materials undoubtedly grew quickly during this period since official prices did not keep up with the underlying inflation rate.

In measuring nominal material inputs, we use data on purchases rather than data on the value of materials used in production..$^{15}$ It is the purchase of materials, rather than their use, that makes them unavailable to the rest of the economy. Under this approach, extra output produced using materials withdrawn from inventory is taken to be an efficiency gain. If, without the reforms, these materials would have remained in inventory indefinitely, as seems likely given the incentives firms faced under the prior regime to hoard inputs, then withdrawal from inventories does indeed produce an efficiency gain. If newly purchased inputs added to inventory will be used at a later date, then the true production process has a dynamic element which for simplicity we ignore.

Nominal material inputs were reexpressed in 1987 prices, using the estimated inflation rates, to get real material inputs. Our measure of the relative amounts of material inputs used by different firms is in error to the degree to which different firms received different relative discounts from market prices for these inputs in 1987, or at least reported different relative discounts under expenditures for materials. For example, the price of inputs allocated through the plan would normally be very low, and planned allocations differ by firm. ${ }^{16}$

The annual percent change in real material inputs is reported in Table 3 , while the overall percent change in real material inputs from 1983 to 1987 is reported in Table 4, by industry. In most industries, the percent increase in real material purchases during the period was much smaller than the percent increase in real sales.

\subsection{Capital Input, $K_{e 3 s}$}

Measuring real capital inputs presents a variety of extra complications. First, the information about inflation in capital costs is much more scanty. The only direct information available 
in the survey comes from responses to a set of questions about capital costs asked of each manager. If the firm had continued to buy a similar type of machinery over a period of years, the manager was asked what the prices were at the earliest and the latest dates at which this type of machinery was purchased. In particular, firm $e$ reports purchases in year $s$ and year $s^{\prime}$ at prices $\theta_{s}$ and $\theta_{s^{\prime}}$ respectively.

We used the set of answers to these questions provided by all the firms in the sample to estimate the aggregate inflation rate for capital prices, $\pi_{s}^{K}$, in each year $s$. In particular, if the inflation rates, $\pi_{s}^{K}$, are the same for all firms, then $\theta_{s^{\prime}} / \theta_{s}=\exp \left(\Sigma_{r=s+1}^{s^{\prime}} \pi_{r}^{K}\right)$, implying that $\log \left(\theta_{s^{\prime}} / \theta_{s}\right)=\Sigma_{r=s+1}^{s^{\prime}} \pi_{r}^{K}$. Let $R(e)=\log \left(\theta_{s^{\prime}} / \theta_{s}\right)$, and let $D_{r}(e)=1$ if $s<r \leq s^{\prime}$ for firm $e$ and let $D_{r}(e)=0$ otherwise. We then regressed the vector $R$ on all the $D_{r}{ }^{\text {'s. }}{ }^{17}$ The coefficient on $D_{r}$ should equal the inflation rate in capital prices between year $r-1$ and year $r$.

Unfortunately, the amount of information available was not sufficient to estimate all these coefficients reliably. We therefore imposed the constraint that the inflation rate follow a piecewise-linear pattern across time between 1974 and 1984, with change in slope in years 1979,1981 , and $1984 .^{18}$ In addition, given other evidence of stable prices prior to the reforms, ${ }^{19}$ we imposed the further constraint that the inflation rate was zero until after $1979 .{ }^{20}$ The resulting coefficient estimates for the time path of the inflation rate are reported in Table 5. Overall, these estimates seem very reasonable. Inflation was low in the early $1980 \mathrm{~s}$, but hit double digits in 1984-1985, dropped in 1986 as credit tightened, then jumped again thereafter as controls relaxed.

These estimates are much higher than the inflation rates in output prices for industries producing machinery and equipment, reported in Table 2, a result analogous to that found for materials. Part of the explanation here may be that some of the data used in the regression refer to prices of imported machinery, ${ }^{21}$ whereas the data in Table 2 are solely for domestically produced machinery. Another possibility, as before, is that firms selling machinery understate their revenue by reporting only the cash component of the sale, whereas managers report in the survey the total cost of the machinery purchased. We chose to use the regression results for the inflation rate for machinery, rather than data from Table 2 ,

Table 5. Equipment price inflation regression.

\begin{tabular}{|c|c|c|}
\hline $\begin{array}{c}\text { Time } \\
\text { Dummies }\end{array}$ & $\begin{array}{c}\text { Estimated } \\
\text { Coefficients }\end{array}$ & $\begin{array}{c}\text { Standard } \\
\text { Error }\end{array}$ \\
\hline D80 & -.0265 & .0347 \\
\hline D81 & -.0529 & .0694 \\
\hline D82 & .0173 & .0274 \\
\hline D83 & .0848 & .0467 \\
\hline D84 & .1577 & .0954 \\
\hline D85 & .1834 & .1230 \\
\hline D86 & .0429 & .1214 \\
\hline D87 & .2478 & .1014 \\
\hline D88 & .1577 & .0795 \\
\hline Constant & .1133 & .1044 \\
\hline$R^{2}$ & \multicolumn{2}{|c|}{.2175} \\
\hline Observations & \multicolumn{2}{|c|}{142} \\
\hline
\end{tabular}


under the assumption that the accounting data also report the total cost, rather than the cash cost, of machinery and equipment purchased.

The regression estimates the inflation rate only for machinery prices. Our only information about the inflation rate for the cost of structures comes from the data on output prices for firms producing building materials. To calculate an overall inflation rate in a given year for productive investment for each firm, we took a weighted average of these inflation rates for machinery and structures, weighting the inflation rate for machinery by the amount spent by the firm on equipment as a fraction of total productive investment. The aggregate yearly inflation rate for productive investment is reported in Table 1. Capital input prices grew more quickly than either material prices or output prices.

To measure the change in real capital inputs between one year and the next, we first converted nominal investment in productive assets in each year into real investment in 1987 prices using the annual inflation rates, as calculated above. Denote the real investment in year $s$ by $I_{s}$. We assumed that capital investment occurs at a smooth rate during the year, implying that on average investment taking place in $s$ is available for use during only half of year $s$. Given this assumption, new investment leads to a gross increase in the available capital between years $s-1$ and year $s$ of $.5\left(I_{s-1}+I_{s}\right)$. This is the procedure we use to measure the change in capital inputs when estimating equation (4).

To calculate the growth rates in capital inputs and the various productivity measures, we also needed to estimate the capital stock in each year for each firm. We started with the firm's reported figure for year-end fixed productive assets in 1983, valued at purchase prices. By subtracting productive investment in 1983, we have an estimate of the beginningof-year capital stock, valued at purchase prices. ${ }^{22}$ We then converted this estimate of the beginning-of-year capital stock in 1983 to 1987 prices using the estimated inflation rates for productive investment between 1983 and 1987. To get the average amount of real capital in 1983, we then added back half of the real investment that occurred during 1983. The average amount of real capital in each later year is then derived by adding on our estimate of the change in real capital for that firm, as calculated above.

There may be two sources of error in these figures. First, the data on year-end fixed productive assets in 1983 do not include prior investment in projects still under construction. To measure the opportunity cost of the resources committed to the firm, past expenditures on uncompleted projects should be included. In addition, the above procedure does not take into account any sales by the firm of capital assets during the sample period, or any capital that is scrapped. Unfortunately, the available data does not allow us to correct for these problems. The first problem leads to an underestimate of the capital stock, while the second leads to an overestimate.

These figures also ignore depreciation. By doing so, we assume that the productivity of each piece of capital remains unchanged over time, as would be implied by a one-hossshay-technology, and that maintenance costs do not vary with age. Certainly, casual evidence suggests that the effective lifetime of capital is much longer in China than in the U.S. The arbitrary nature of the depreciation figures reported in the survey gave us no satisfactory alternative. ${ }^{23}$ In addition, we ignore technological change. If more productive technologies are priced accordingly, then our approach should be satisfactory.

As with materials, we are not able to take into account differing discounts from market prices received by firms when purchasing new capital. Fortunately, government subsidies 
to capital purchases normally take the form of direct grants to cover the purchase of the capital or available bank loans at low interest rates (often with repayments deductible from taxable income), rather than reduced purchase prices for new capital. Barter trade may still create problems, however.

Table 3 reports the annual growth rate in the aggregate real capital stock, while Table 4 reports the overall growth rate in the capital stock between 1983 and 1987, by industry. The aggregate percent increase in real capital inputs was somewhat higher than the percent increase in output, particularly in 1986-1987, though this was not always true industry by industry-in both the machinery and the electronic industries, output grew more quickly.

\subsection{Regulatory Policies, $X_{\text {ejs }}$}

Initially, in estimating equation (4) we include just a constant term to capture the overall percent increase in output not explained by increases in factor inputs. This captures adequately broad policy changes affecting the bulk of the firms in the sample, such as the broad shift to explicit taxes by 1984 and the shift to contracts in 1986-1987. It ignores, however, policy changes affecting only subsets of the firms.

We therefore estimate a second version of equation (4) in which we include variables capturing the impact of a few specific policies on productivity growth. To begin with, firms acquired at different times the flexibility to make various economic decisions without government approval. In the survey, each firm's manager reports the year in which his firm acquired the right to make each of six operational decisions. These decisions were: 1) output price, 2) output quantity, 3) composition of goods produced, 4) technology used in production, 5) timing of the production process, and 6) amount to be exported.

Generally, the right to make the first five decisions was received simultaneously, whereas the right to control exports was more unusual and granted much later. ${ }^{24}$ We calculated the average of the reported years in which each of the first five rights were received. If this average date were prior to 1983 , then we set $\Delta_{t s} X_{e 1}$ to one, and set it to zero otherwise. This variable therefore captures the differing productivity growth of those firms that had already acquired the right to make decisions by the beginning of our sample period. For those firms that acquired the right during the sample period, we set $\Delta_{t s} X_{e 2}$ equal to the number of years during the sample in which they had this flexibility. The longer the firm had this flexibility, the larger the presumed effect.

The timing of the effects of this type of decentralization can be complicated. If, in response to the new flexibility, firms choose to shift the type of goods they produce, or the technology they use, then output may fall initially as the retooling takes place. Also, the decentralization of decisions would likely be accompanied by a loss of the right to sell all output to a state purchasing agency, leading to an initial drop in sales until customers can be located. When firms know ahead the date of this decentralization, they may even start to retool ahead of time. Given the limited amount of data we had, however, we did not attempt to capture any nonlinearities in the effects of this variable.

Firms also differed in the fraction of profits they could retain. The larger this fraction, presumably the larger the incentive to improve efficiency. ${ }^{25}$ We therefore defined $\Delta_{t s} X_{e 3}$ to equal the average ratio of retained profit to realized profit during 1983-1987. 
Finally, we added dummy variables to capture the effects of recent policy experiments. In particular, we set $\Delta_{t s} X_{e 4}$ to one if the firm was under the contracting system as of the date of the interview, and set it to zero otherwise. Similarly, $\Delta_{t s} X_{e 5}$ was set equal to one if the firm was participating in the assets management responsibility system, and $\Delta_{t s} X_{e 6}$ was set equal to one if the firm was participating in the factory manager responsibility system.

\section{Results}

\subsection{Estimation of Equation (4)}

We estimated three versions of equation (4). The dependent variable was the fraction by which that firm's real output grew from 1983 to 1987 . For each input, we included as an independent variable the change in the real amount of that input available to the firm between 1983 and 1987, divided by that firm's real output in 1983. The set of $Z_{k i}^{e}$ and $\Delta_{t s} X_{e j}$ variables included varied by specification. We chose to focus on the overall change during the reform period, rather than on the year-by-year changes, in order to reduce any biases arising from our neglect of the potentially complicated timing of the impact of additional inputs on output, ${ }^{27}$ and from the short panel we have.

The base sample of firms used included all firms with adequate data for that regression. After deleting firms with missing data or extreme outliers, ${ }^{28}$ we had a sample of 285 firms for the first regression, out of an original sample of 403, 281 firms for the second regression, and 280 firms for the third regression. Regression results appear in Tables 6 and 7 . In the first specification, in addition to the variables measuring changes in factor input, we set $Z_{1 i}^{e}=\left(\Delta_{t s} K_{e i} / Q_{e s}\right)$, leading us to include the square of this varaible for each of the factors. A constant term is included to capture the effects of the regulatory changes. In the results, reported in column 1 of Table 6 , we find from the constant term that in aggregate firms experienced a $16.7 \%$ increase in output during the period beyond what can be explained by increased inputs. (The standard error of this estimate is very small.) As seen in equation (8), this estimate of the constant term is proportional to the change in overall productivity growth if the initial value of II in 1983 were equal to one. ${ }^{29}$ We return later to examine productivity growth figures in more detail.

By including the $Z_{1 i}^{e}$ terms, we allowed the marginal products of each factor to vary by firm, as a function of the actual change in inputs, to test whether there was any systematic tendency to allocate more inputs to more efficient firms. If more efficient firms did get more inputs, then the coefficient of the squared value of the change in each input, as a fraction of initial output, should be positive. We find that this coefficient is positive and statistically significant only for materials-it is small and insignificant for labor and capital. $^{30}$ These findings are not surprising. Markets were set up for material inputs during this period, so in spite of the continuing allocation of some materials through the plan, market forces could still shift materials significantly toward firms where their marginal product was higher. But labor and capital used in the state sector during this period continued to be allocated primarily by higher authorities.

Our estimate for the marginal product of materials varies from 1.07 in the electronics industry to .99 in the building materials industry; ${ }^{31}$ the weighted average value of the 
Table 6. Productivity regressions-versions I and II.

\begin{tabular}{|c|c|c|c|c|}
\hline \multirow[b]{2}{*}{ Explanatory Variables } & \multicolumn{2}{|c|}{ I } & \multicolumn{2}{|c|}{ II } \\
\hline & Coefficients & Standard Error & Coefficients & Standard Error \\
\hline$\frac{\Delta L}{Q}$ & 2.3065 & 1.3167 & 2.0322 & 1.3131 \\
\hline$\left[\frac{\Delta L}{Q}\right)^{2}$ & -1.3678 & 4.2025 & -7.7695 & 4.2202 \\
\hline$\frac{\Delta K}{Q}$ & .0827 & .0761 & .0812 & .0779 \\
\hline$\left(\frac{\Delta K}{\bar{Q}}\right)^{2}$ & .0219 & .0157 & .0240 & .0159 \\
\hline$\frac{\Delta M}{Q}$ & 9919 & 0871 & 1.0238 & .0897 \\
\hline$\left(\frac{\Delta M}{Q}\right)^{2}$ & .1139 & 0477 & .0998 & .0483 \\
\hline Decentralized Before 1983 & - & - & -.0584 & .0715 \\
\hline Years of Decentralization & - & - & .0158 & .0198 \\
\hline Retention Rate & - & - & -.1361 & .1401 \\
\hline D (Responsibility) & - & - & .0141 & .0860 \\
\hline D (Asset Responsibility) & - & - & .1728 & .1179 \\
\hline D (Manager Responsibility) & - & - & .0589 & .0867 \\
\hline Constant & .1674 & .0355 & .1595 & .0889 \\
\hline$R^{2}$ & & & & \\
\hline Observations & & & & \\
\hline
\end{tabular}

Table 7. Productivity regression-version III.

\begin{tabular}{|c|c|c|}
\hline \multirow[b]{2}{*}{ Explanatory Variables } & \multicolumn{2}{|c|}{ III } \\
\hline & Coefficients & Standard Error \\
\hline$\frac{\Delta L_{\text {college }}}{Q}$ & 13.2905 & 17.0154 \\
\hline$\frac{\Delta L_{\text {senior-hi }}}{Q}$ & 8.6939 & 2.8221 \\
\hline$\frac{\Delta L_{\text {junior-hi }}}{Q}$ & -.5145 & .5569 \\
\hline$\frac{\Delta K}{Q}$ & .1485 & .0448 \\
\hline$\frac{\Delta M}{Q}$ & 1.1364 & .0603 \\
\hline Constant & .0828 & .0322 \\
\hline$R(2)$ & & \\
\hline Observations & & \\
\hline
\end{tabular}


marginal product for each input, estimated using equation (6), equals 1.01 . This is remarkable since efficient resource allocation argues that materials should be used until the value of their marginal product equals their cost. Since we have measured material inputs based on their cost, efficient resource allocation implies that their marginal product should equal 1.0 , which is just what we find. How can this be reconciled with persistent complaints of material shortages leading to production stoppages? For one thing, this is an estimate of the value of the marginal product of materials as a group. The marginal product of electricity may be much higher, and that of other material inputs may be much lower. In addition, firms may report true input prices but underreport true output prices, leading us to underestimate the true value of the marginal product of materials.

Our coefficients imply that the weighted average real return to capital equals $9.3 \%$ per year, before depreciation. While the standard error of this estimate is almost as large, this estimate still implies that the return to capital is very low by international standards. This may in part reflect the sizable amount of new investment going into uncompleted projects, as well as the expenditures on company cars and other perquisites that do not raise observed output. These estimates are certainly consistent with the view that the government has unduly favored investment over consumption, leading to substantial overinvestment. However, the coefficients may also simply reflect lags in the impact of new investment on output not taken into account in the specification. Finally, we may underestimate the value of the marginal product of capital because firms underreport the value of their output compared with the costs of their inputs.

Finally, our estimate of the value of the marginal product of labor is 2303 yuan per year. In contrast, the average wage per worker in the sample, including bonuses, was only 1806 yuan per year in 1987. However, the nonproductive capital, primarily housing, allocated to these workers had an opportunity cost of 576 yuan per year, implying a total implicit income of these workers of 2382 yuan per year. ${ }^{32}$ Together, these figures imply an implicit $3.2 \%$ wage subsidy. ${ }^{33}$

Our estimates of the marginal products of each factor seem remarkably close to the actual pay received by each factor. This is just what should occur under a competitive market system. In spite of the lack of explicit factor markets, one possible conclusion is that allocations approximate what would occur with such markets. There may be a very different explanation, however. Official prices in China are normally set equal to a mark-up over average costs. If the mark-up rate is $\gamma$, then by construction $Q_{e s}=\gamma \Sigma_{i} r_{i s} K_{i s}$, where $r_{i s}$ is now interpreted to equal the accounting cost of input $i$ used in setting prices in period $s$. As a result,

$$
\Delta_{t s} Q_{e}=\gamma \sum_{i} r_{i t} \Delta_{t s} K_{i}-\left[Q_{e s}-\gamma \sum_{i} r_{i t} K_{i s}\right]
$$

Here, the term in parentheses measures the profits that would have been earned in period $s$ if prices had been set at their values in period $t$. In period $t$, at these prices, the firm broke even by construction. If there had been productivity growth between periods $s$ and $t$, this term would be negative, implying a positive constant term in equation (10). Therefore, if the data were determined by equation (10), so that reported sales revenue is entirely based on official prices, then our estimates of the $r_{i}$ should simply equal the accounting 
costs for each input used in setting prices in period $t$, times $\gamma$. This seems to be a plausible explanation for our results.

In the second specification we tried in addition to estimate the effects of specific policy changes. These attempts proved to be less successful-the standard errors of these estimates were large enough that even coefficients implying important effects on productivity would not be statistically significantly different from zero. In any case, the only coefficient large enough to imply an economically important impact on productivity is the dummy variable for those firms under the asset management responsibility system. According to our estimates, these firms experienced an additional $17 \%$ increase in productivity beyond that found for other firms. Given that this experiment occurred late in the sample interval, this change is very large, though the standard error of the estimate is also quite large.

In the final specification, we allowed the marginal product of labor to vary by education. This was done by adding appropriately defined dummy variables as $Z_{k i}^{e}$ variables, and dropping the $X_{e j}$ and the squared changes in input terms, given their lack of importance in the specification. Here, we find that the estimated marginal product of labor varied substantially with education..$^{34}$ Controlling for the change in the quality of the labor force also caused the constant term to fall in half, suggesting that about half of the overall productivity growth was due to the improvement in the quality of the labor force.

Our finding that measured policy changes had statistically insignificant impact on productivity does not necessarily mean that the reforms had negligible impact. The reforms undertaken in China affected most state enterprises at roughly the same time. As a result, we find that there was too little variation in the timing or the form of the reforms affecting different firms to allow their effect to be estimated using our approach. Most of the impact of the policy changes is therefore simply captured by the intercept term in the regression. Controlling for changes in the composition of the labor force, our estimates suggest a productivity growth of $2.05 \%$ per year between $1983-1987$ that can potentially be attributed to the reforms. While our estimation approach has not proven capable of linking specific reforms to the observed productivity growth, a closer examination of the timing of the productivity growth during the period, and a study of the detailed behavior of firms in response to the reforms, may still potentially provide evidence of the role that the reforms played in the observed productivity growth.

\subsection{Productivity Measures}

These regression estimates allow us to calculate the opportunity cost of each of the inputs, $r_{i}$. Using the procedure described by equation (6), we set the opportunity cost of labor equal to 2303 yuan per year. Similarly, the opportunity rate of return on capital was set equal to $9.3 \%$, while the opportunity cost of materials was set equal to 1.01 per yuan of materials.

Given these estimates, we then calculated the values of the productivity measure for each industry for both 1983 and 1987. These are reported in Table 8 for the sample of 274 firms for which all needed data were available. Here, we find that in 1983, the aggregate productivity measure equals 1.07 , implying that in aggregate revenues and economic costs were very close in 1983. 
Table 8 . Productivity by industry.

\begin{tabular}{lrrr}
\hline \multicolumn{1}{c}{ Industry } & \multicolumn{3}{c}{ Productivity } \\
\cline { 2 - 4 } \multicolumn{1}{c}{} & 1983 & 1987 & Percent Change \\
\hline Mining & 1.31 & 1.33 & 1.44 \\
Utility & .70 & .65 & -8.13 \\
Food and Fodder & 1.07 & .96 & -10.34 \\
Beverage and Tobacco & 1.98 & 2.15 & 8.89 \\
Textile & .91 & 1.00 & 9.50 \\
Other Light & .88 & .98 & 10.61 \\
Chemical & 1.08 & 1.11 & 2.76 \\
Building Materials & 1.02 & 1.17 & 14.16 \\
Metallurgy & .92 & 1.36 & 48.70 \\
Machinery & .95 & 1.11 & 16.88 \\
Electric Equipment & 1.07 & 1.11 & 3.56 \\
& & & 19.96 \\
Sample Average & 1.07 & 1.28 & \\
\hline
\end{tabular}

The value of the productivity measure in 1983 varies to some degree by industry, however. In particular, its value ranges from 1.98 in the beverage and tobacco industry to 0.70 in the utilities industry. In each of these two cases, differences from the aggregate value probably can be explained by systematic deviations in the observed prices in 1987 from social values. In particular, the first industry is largely alcohol and tobacco, where prices are kept artificially high to discourage use. The social value of the output of this industry would plausibly be much lower than the market value. Similarly, the price of electricity has been kept artificially low, implying that the measured value of the output of the utilities industry undoubtedly understates its social value. THe values of the productivity measure for most of the other industries are tightly bunched around the economy-wide value.

By 1987, the aggregate value of the productivity measure had increased from 1.07 to 1.28 , implying productivity growth of over $4.6 \%$ per year between 1983 and 1987 , for an aggregate growth of $20 \%$. Since real output of these firms grew by $8.7 \%$ per year during this period, we estimate that over half of the total growth results from a growth in productivity.

While aggregate productivity grew by $20 \%$ during this period, however, most industries experienced much smaller productivity growth. Metallurgy experienced a dramatic $48.7 \%$ increase in productivity, and there was a sizable improvement in both building materials and other light industries, but productivity increased by less than $10 \%$ in other industries and even fell in the utilities and food and fodder industries. Since $37.6 \%$ of the aggregate social cost of inputs were allocated to the metallurgy industry between 1983 to 1987 , the productivity growth in this section has a major influence on the aggregate figures.

The overall increase in productivity also appears to result in part from a shift in resources away from industries with low productivity and toward industries with high productivity. The aggregate social costs of real inputs grew by $37.3 \%$, but it grew by $57.3 \%$ in beverages and tobacco (the most productive industry) and grew by only $26.4 \%$ in the utilities industry (the least productive industry). ${ }^{35}$ 


\section{Conclusions}

What happened to the productivity of Chinese state enterprises between 1983 and 1987 ? Based on the estimates we have obtained from a sample of 285 firms, we find that productivity increased by $4.6 \%$ per year during this period. About half of this productivity growth appears due to the rapidly improving educational level of the labor force in these firms. Since real output grew by $8.7 \%$ during the same period, over half of the growth in output appears to have arisen from growth in productivity.

At this point, we have been unsuccessful in pinpointing what specifically led to this productivity growth. Many policies changed during this period, but we found that there was too little variation in the timing or the form of these policy changes among our sample of firms to estimate adequately the impact of specific policies. There was limited evidence, however, that the asset management responsibility system raised productivity significantly.

We also estimated the value of the marginal products of labor, capital and materials during this period. The estimated value of the marginal product of materials just equaled its costs, suggesting an efficient supply of materials. The value of the marginal product of labor was estimated to be 2303 yuan per year, while the actual average pay per worker, plus housing benefits, in 1987 was 2382 per year, implying a very low implicit subsidy to labor. Finally, capital was estimated to earn a real rate of return of $9.3 \%$ per year before depreciation, which is very low by international standards.

\section{Acknowledgments}

We would like to thank two anonymous referees and participants in a conference at Shenzhen, sponsored by the Institute of Economics at the Chinese Academy of Social Sciences, for comments, and to thank the Ford Foundation for financial support for the project.

\section{Notes}

1. Under the responsibility system, farmers could sell at market prices whatever production they had left over, after delivering their quota production to the government at planned prices.

2. However, more profitable firms do not necessarily have more profitable new projects.

3. Further information about this data set can be obtained from the authors on request.

4. This literature dates back to Solow (1957) and Arrow, Chenery, Minhas, and Solow (1961). For applications to market economies, see Gollop and Jorgenson (1980), Gordon, Schankerman and Spady (1986), and Griliches and Mairesse (1984) among many others. For applications to China, see Chen, Wang, Zheng, Jefferson, and Rawski (1988), Dollar (1990), Jefferson (1989) and Lee (1990) among others.

5. Our finite-difference approach is similar to that in Griliches and Mairesse (1983). Griliches and Mairesse estimated the marginal return to R\&D by assuming that the marginal return is identical across firms rather than assuming that the output elasticity of R\&D is identical across firms. In their estimation, however, the production function was still assumed to be Cobb-Douglas in labor input and capital input.

6. To the degree to which the true value of $\nu_{e}$ is correlated with the included right-hand-side variables, coefficients have to be interpreted accordingly.

7. We saw no plausible instruments for the government's choices for either the firm's factor inputs or the firm's regulatory regime. 
8. While the value of $\Pi_{s}$ would equal one if the economy were perfectly competitive and all firms had constant returns to scale, in general its value will differ from one.

9. Even if relative prices in 1987 were closer to relative market prices than were prices in earlier years, important differences still remain. The extent of market trade differs by industry, leading to an undervaluation of the output of more tightly controlled industries. In addition, output is often sold for a combination of goods and money, yet the financial accounts appear to include just the cash component of sales. The value of output that is exported is also likely to be measured poorly, since any difference between the foreign and the domestic price normally went to a Foreign Trade Company rather than the manufacturer. Productivity is therefore judged based on these reported prices rather than based on the prices faced by the ultimate user of the output.

10. Sufficient data were available to calculate $\pi_{e s}$ for 254 firms in 1987, 250 firms in 1986, 245 firms in 1985, and 168 firms in 1984.

11. The firm was dropped from the analysis if nominal sales was missing in either 1983 or 1987.

12. Recall that education virtually stopped in China during the period 1967-1976 because of the Cultural Revolution-colleges in particular reopened only in 1978. As a result, the observed rapid increase in the number of educated workers is not surprising.

13. Sufficient data were available to calculate the inflation rate for 304 firms in 1987,284 firms in 1986,269 firms in 1985, and 190 firms in 1984. If sufficient data were missing, the inflation rate was set equal to the weighted average value across firms with adequate data, weighting by expenditures on materials.

14. Due to barter trade, only part of the payment for materials may be in cash. Supplementary noncash payments may show up in the accounts, but under nonbusiness expenditures rather than material expenditures. Similarly, the revenue from the resale of materials would likely show up as nonbusiness income. Since these categories include a variety of items, we cannot observe supplementary payments or resales, so cannot undo these measurement problems.

15. Specifically, we set nominal material inputs equal to nominal purchases of materials, fuel, and power, plus the value of materials provided by customers for processing. The firm was dropped from the analysis if this figure was unavailable in either 1983 or 1987.

16. Firms that are allocated more materials at planned prices also normally must sell more of their output at planned prices. Therefore, the bias from the understatement of inputs due to the continuing role of the plan should offset the understatement of output due to the plan.

17. A firm was included if year $s$ were no earlier than 1974 and no later than 1987, and if both price figures were available. In total, data were available for 142 firms.

18. The value of the F statistic for these constraints was .536, with a critical value of 6.88 , so that these constraints were easily accepted.

19. See, for example, Jefferson et al. (1988).

20. The $F$ statistic for this constraint was 0.47 , with a critical value of 9.02 , easily accepting this additional constraint.

21. Firms may not be charged the world-market cost of imported machinery, however, or at least may not report the opportunity cost based on market exchange rates.

22. Given the low inflation rate in capital costs prior to 1983 , as seen in Table 5, there should be relatively little error from measuring values at purchase prices rather than replacement costs.

23. Our estimation also confirms this evidence. In a slightly altered specification, we estimate the implicit depreciation rate $\delta$ by specifying the increase in real capital stock between year $s$ and year $t$ in equation (4) by

$$
\Delta_{t s} K_{e}=I_{e}-\delta K_{e s}
$$

where $I_{e}$ measures new investment between years $s$ and $t$, and $K_{e s}$ is the gross real capital stock in year $s$. The estimated $\delta$ is .00034 or $.034 \%$ with a standard error .019 . This result strongly suggests that the implicit depreciation rate in Chinese state enterprises is negligible.

24. During our sample period, most state enterprises did not have direct access to international markets. Foreign trade in China was monopolized by the Foreign Trade Companies, which procured exportable goods at domestic prices from state enterprises and kept any profits generated when these goods were sold to foreigners. Only in $1988 \mathrm{did}$ China begin to decentralize foreign trade and allow exporters to directly market their products overseas. Given that our sample ended in 1987 , we therefore did not make use of this measure of enterprise autonomy in our study. 
25. The average amount of profits retained could well differ from the amount retained from an extra dollar of pretax profits. We felt, however, that the firm's forecast of its average tax payments in the future would be determined in large part by its past average tax payments rather than by the statutory construction of its marginal tax rate.

26. A detailed description of each of these experiments can be found in Lee (1990).

27. For example, additional workers need to be trained, implying an initial drop in output after they are hired, as other workers spend time on this training. Only after this training is complete does output grow in response to the added work force.

28. We eliminated five firms that had values for the dependent variables, or for one of the three independent variables measuring the change in real input divided by 1983 output, that exceeded ten.

29. The calculated value of $\Pi$, reported below, is in fact 1.07 .

30. This is certainly consistent with marginal products of labor and capital having been equalized, as would occur under efficient resource allocation, though it would be premature to conclude this, given that we have explored only one dimension along which marginal products might vary.

31. The variation across firms, however, is much larger; the marginal product of materials ranges from 0.9 to 1.6 across enterprises included in the regression.

32. In addition, workers receive health insurance, pensions, and other nonwage benefits from the firm, but these expenditures are more difficult to extract from the accounts.

33. Workers are still subject to turnover tax payments, however.

34. Wages, in constrast, were tightly controlled by the government in China and varied little with education. According to Knight and Song (1991), for example, college graduates earned only $2 \%$ more than high school graduates in 1986 , and only $3 \%$ more than middle school graduates.

35. To the extent that the social value of the output of these industries is mismeasured, this source of productivity growth may be artificial.

\section{References}

Arrow, K.J., H.B. Chenery, B.S. Minhas, and R.M. Solow. (1961). "Capital-Labor Substitution and Economic Efficiency." Review of Economics and Statistics 43, 225-250.

Atkinson, S.E. and R. Halvorsen. (1984). "Parametric Efficiency Tests, Economies of Scale, and Input Demand in U.S. Electric Power Generation." International Economic Review 25, 647-662.

Atkinson, S.E. and C. Cornwell. (1994). "Parametric Estimation of Technical and Allocative Inefficiency with Panel Data." International Economic Review 35, 231-243.

Bauer, P.W. (1990). "Recent Developments in the Econometric Estimation of Frontiers." Journal of Econometrics 46, 39-56.

Chen, K., H. Wang, Y. Zheng, G.H. Jefferson, and T.G. Rawski. (1988). "Productivity Change in Chinese Industry: 1953-1985." Journal of Comparative Economics 12, 570-591.

Dollar, D. (1990). "Economic Reform and Allocative Efficiency in China's State-Owned Industry." Economic Development and Cultural Change 39, 89-105.

Gollop, F.M. and D.W. Jorgenson. (1980). "U.S. Productivity Growth by Industry, 1947-73." In J.W. Kendrick and B. Vaccara (eds.), New Developments in Productivity Measurement: Studies in Income and Wealth 44, $17-136$. Chicago: University of Chicago Press.

Gordon, R.H., M. Schankerman, and R. Spady. (1986). "Estimating the Effects of R\&D on Bell System Productivity.' In M. Peston and R. Quandt (eds.), Festschrift in Honor of William Baumol. Oxford: Philip Allan.

Griliches, Z. and J. Mairesse. (1983). "Comparing Productivity Growth: An Explanation of French and U.S. Industrial Firm Data." European Economic Review 21, 89-119.

Jefferson, G.H., T.G. Rawski, and K. Chen. (1988). "New Estimates of Fixed Investment and Capital Stock for Chinese State Industry." China Quarterly 114, 243-266.

Jefferson, G.H. (1989). "Potential Sources of Productivity Growth within Chinese Industry." World Development $17,45-57$.

Kendrick, J. (1973). Postware Productivity Trends in the United States 1948-1969. New York: Columbia University Press. 
Knight, J. and L. Song. (1991). "The Determinants of Urban Income Inequality in China." Oxford Bulletin of Economics and Statistics 52, 123-154.

Kumbhakar, S.C. (1992). "Allocative Distortions, Technical Progress and Input Demand in U.S. Airlines: 19701984." International Economic Review 33, 723-737.

Lee, K. (1990). "The Chinese Model of the Socialist Enterprise: An Assessment of Its Organization and Performance." Joumal of Comparative Economics 14, 384-400.

Lovell, C.A.K. And R.C. Sickles. (1983). "Testing Efficiency Hypotheses in Joint Production: A Parametric Approach." Review of Economics and Statistics LXV, 51-58.

Schmidt, P. and C.A.K. Lovell. (1979). "Estimating Technical and Allocative Inefficiency Relative to Stochastic Production and Cost Frontiers." Journal of Econometrics, 9, 343-366.

Sickles, R.C., D. Good, and R.L. Johnson. (1986). "Allocative Distortions and the Regulatory Transition of the U.S. Airline Industry." Journal of Econometrics 33, 143-163.

Solow, R.M. (1957). "Technical Change and the Aggregate Production Function." Review of Economics and Statistics 39, 312-320.

State Statistical Bureau. (1989). China Statistical Yearbook of Prices. China Statistical Publishing House.

White, H. (1989). "A Heteroskedasticity-Consistent Covariance Matrix Estimator and a Direct Test for Heteroskedasticity." Econometrica 48, 817-838. 